Ecological Economics, 1999, Volume 29, Issue 3, Pages 349-358.

ISSN: 0921-8009

http://www.elsevier.com/wps/find/journaldescription.cws home/503305/description\#description

(C) 1999 Elsevier Science B.V. All rights reserved.

\title{
Balancing conservation and economic gain: a dynamic programming approach
}

Paul F. Doherty Jr., Elizabeth A. Marschall, Thomas C. Grubb Jr.

Department of Evolution, Ecology and Organismal Biology, The Ohio State University.

\begin{abstract}
We optimize the trade-off between economic and ecological concerns in conservation biology by using a novel method to link a spatially explicit individual-based model to a dynamic programming model. To date, few optimality models have been presented to optimize this trade-off, especially when the common currency cannot be easily measured in dollars. We use a population simulation model (e.g. spatially explicit individual-based model) to model a hypothetical forest bird population's response to different cutting and planting regimes. We then link these results to a dynamic programming model to determine the optimal choice a manager should make at each time step to minimize revenue foregone by not harvesting timber while maintaining a given population of birds. Our results show that if optimal management choices are made further back in time, future (terminal) reward may be greater. As the end of the management period approaches, past management practices influence the terminal reward more than future practices can. Thus if past revenue lost is high, the future reward will be low as compared to when past revenue lost is low. The general strategy of setting some minimum viable population size and then using a population simulator linked to a dynamic programming model to ask how to maintain such a population size with minimum economic loss should have nearly universal applicability in conservation biology.
\end{abstract}

\section{Introduction}

Conflict exists between monetary gain from logging and ecological maintenance of existing communities (northern spotted owl, Strix occidentalis, McKelvey et al., 1992; Bachman's sparrow, Aimophila aestivalis, Liu et al., 1995; Kirtland's warbler, Dendroica kirtlandii, Probst and Weinrich, 1993). Although the structure of this conflict differs across systems, interactions between reductions in woodlot area and the birds inhabiting those woodlots are a common problem across agricultural areas of the country (Whitcomb, 1977; Brawn and Robinson, 1996). Currently, across farming regions, woodland is commonly fragmented into many small privately owned woodlots interspersed within crop fields or pasture. While many bird species exist within this fragmented landscape, further reductions of woodlot area may compromise the ability of woodland-bird populations to maintain themselves. At the same time, failure to cut and harvest the woodlots is also a failure to gain potential monetary income from them.

In the process of evaluating the consequences of human activities, policy makers are often faced with a dilemma because of the contradictory recommendations from ecologists and economists. Conflicts between ecological and economic goals have provoked calls for simultaneous studies of ecological and economic impacts of human activities (Liu, 1993). The Sustainable Biosphere Initiative calls for new theory incorporating economic and ecological principles and more research focusing on the 'economics of exploitation and conservation' (Lubchenco et al., 1991). As Haight (1995) details, such a view is also taken by the USDA Forest Service. The National Forest Management Act of 1976 requires the USDA Forest Service to produce cost-effective, multiple-use forest plans that ensure the viability of native wildlife populations within the planning area. As conflicts between ecological and economic concerns are becoming more frequent, we are being called on 'to bring the full power of our intellectual 
capital to bear on the huge problems we now face (Costanza, 1991; Jansson et al., 1994; Costanza and O’Neil, 1996).

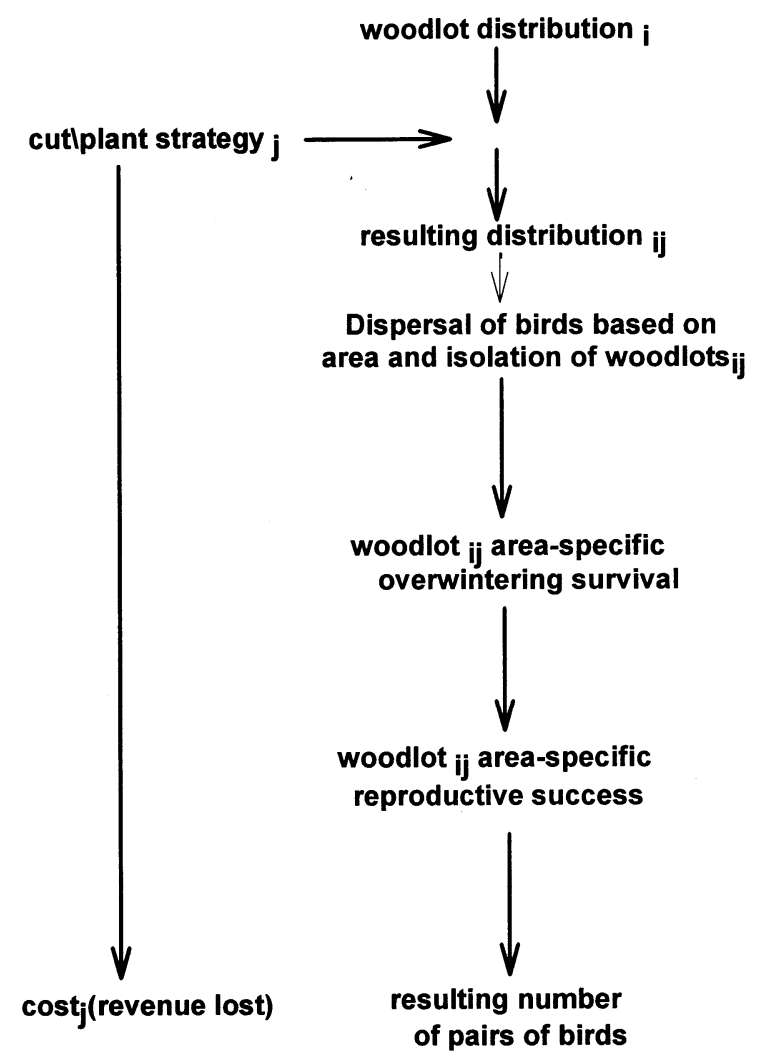

Fig. 1. Flow diagram of the spatially explicit individual-based model for yearly bird survival and reproductive output.

Table 1

Woodlot size class, with area, number of woodlots and bird territories in each class

\begin{tabular}{lll}
\hline $\begin{array}{l}\text { Woodlot size } \\
\text { class }\end{array}$ & $\begin{array}{l}\text { Number of } \\
\text { woodlots }\end{array}$ & $\begin{array}{l}\text { Number of bird terri- } \\
\text { tories per woodlot }\end{array}$ \\
\hline 1 (10 ha) & 60 & 0 \\
$2(15$ ha $)$ & 30 & 1 \\
3 (20 ha) & 15 & 2 \\
$4(30$ ha $)$ & 8 & 4 \\
\hline
\end{tabular}

One of the few species conservation models that incorporates economic as well as ecological data is ECOLOCON (Liu, 1993). This spatially explicit, individual-based simulation model predicts population dynamics as well as economic income based on current taxes and timber markets. Although this model's outputs provide valuable information for balancing the conflict between conservation and economic revenues, it is not an optimality model. It does not provide the optimal trade-off between species protection and financial return; it only simulates what would happen in the future given certain parameter estimates. 
Table 2

Cutting (-) and planting strategies (i) available to a manager, corresponding woodlot size class affected and net cost index

\begin{tabular}{lll}
\hline Cutting $(-)$ or planting strategy $(i)$ & Woodlot size class cut or planted & Relative net cost index (revenue lost) $\left(d_{i}\right)$ \\
\hline-4 & Cut 4 & 1 \\
-3 & Cut 3 & 2 \\
-2 & Cut 2 & 3 \\
-1 & Cut 1 & 4 \\
0 & Do nothing & 5 \\
1 & Plant 1 & 6 \\
2 & Plant 2 & 7 \\
3 & Plant 3 & 8 \\
4 & Plant 4 & 9 \\
\hline
\end{tabular}

More recently, Haight (1995) put forth a decision model that determined how much forest area should be preserved to meet a standard of extinction risk for a focal species and what the estimated economic costs would be. Such a decision model helps in directing research and monitoring activities and in determining an economically efficient standard. Haight's approach (Haight, 1995) links models for forest and wildlife dynamics in a decision model that estimates the economic cost of protection based on an extinction risk standard and a margin of safety. The model estimates how many acres to maintain to meet an extinction risk and margin of safety, how much the land set aside will cost in terms of revenue forgone and when timber harvesting should take place.

Another approach to optimizing the trade-off between economics and conservation goals is to use dynamic programming. Dynamic programming is a set of techniques that solve for an optimal solution to a multi-stage decision process (Bellman, 1957). We use the technique of stochastic dynamic programming as described by Mangel and Clark (1988). It is a discrete-time optimization method usually involving numerical simulation, in which backwards iteration is used to find the long-term optimal strategy. This approach has been employed in agricultural economics (Kennedy, 1986) and, more recently, in modeling animal behavior (Mangel and Clark, 1988). The technique has also been used in modeling optimal human management policy in strictly economic contexts such as commercial fisheries (Gillis et al., 1995), sheep production/grouse shooting (White and Wadsworth, 1994) and Saiga antelope (Saiga tatarica) (Milner-Gulland, 1997) where the 'common currency' is money. While not previously attempted, dynamic programming has great potential in conservation biology either when the common currency cannot be measured in strictly financial units, or when assigning a dollar value to an organism is unsatisfactory.

We link a population simulation to a dynamic programming model for optimizing economic and ecological trade-offs in setting management policy. The purpose of the population simulation is to model how an organism of interest will survive in differing landscapes that result from management choices. The dynamic program predicts what choices should be made by a manager over a certain time horizon. We present a hypothetical example that allows a manager to maintain a viable population of birds while deriving maximum income from harvested timber. To identify cutting and planting practices that will maintain bird populations at minimum loss of potential income, our approach combines individual-based simulations of bird dispersal, annual survivorship, and reproductive success with an optimality model. Clearly, there are any number 
of combinations of indices of bird population status and monetary gain that could be used as the currency in the optimality model. We have chosen a very simple method of combining these two features in our system: the bird population must be maintained above some minimum level, and beyond that level, the manager chooses planting and cutting regimes to maximize the ratio of number of birds to some index of 'revenue lost'. Revenue lost is itself an index representing the difference between the best short-term gain possible (i.e. cut and sell all the woodlots) and the chosen strategy. The index is explained further in Section 2.
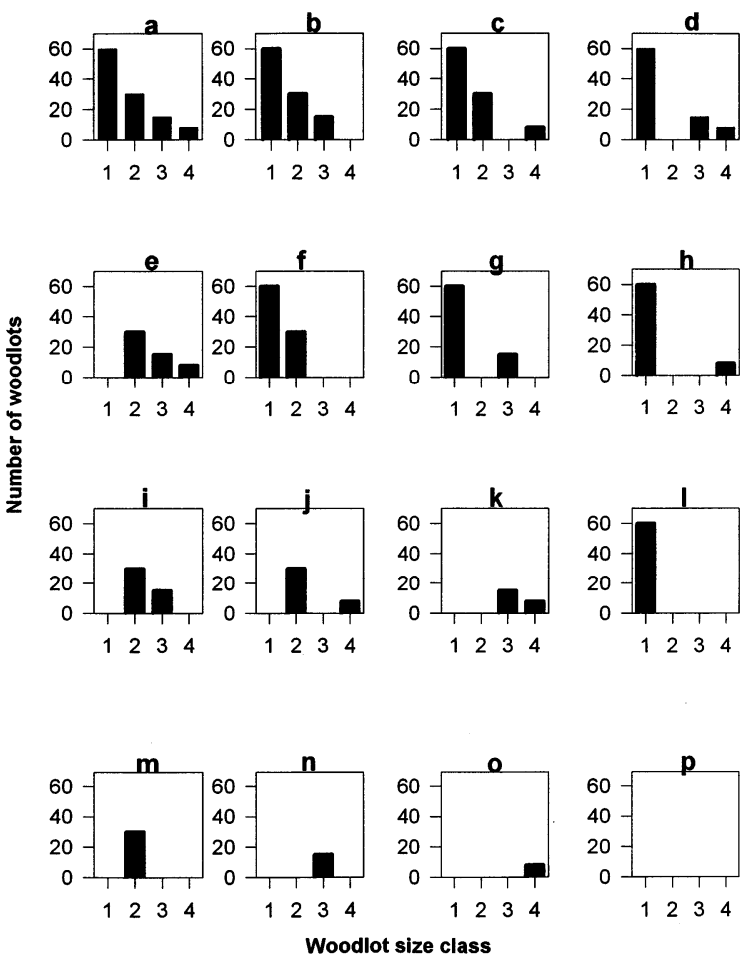

Fig. 2. (a-p) The 16 possible woodlot distributions employed in the models. Each woodlot distribution consists of four size classes: 1 (10 ha), 2 (15 ha), 3 (20 ha) and 4 (30 ha).

Table 3

Probabilities of overwinter survival for bird pairs located in woodlots of different size

\begin{tabular}{ll}
\hline Woodlot size class & $\%$ Survival \\
\hline 1 (10 ha) & 10 \\
$2(15 \mathrm{ha})$ & 80 \\
3 (20 ha) & 90 \\
4 (30 ha) & 99 \\
\hline
\end{tabular}


Table 4

Percentage distribution of reproductive output for breeding pairs of birds located in woodlots of different size

\begin{tabular}{lrrrrrr}
\hline Woodlot size class & \multicolumn{7}{l}{ Number of offspring } \\
\cline { 2 - 7 } & \multicolumn{1}{c}{0} & \multicolumn{1}{c}{4} & 5 & 6 & 7 & 8 \\
\hline $1(10 \mathrm{ha})$ & 100 & 0 & 0 & 0 & 0 & 0 \\
$2(15 \mathrm{ha})$ & 0 & 30 & 30 & 30 & 10 & 0 \\
$3(20 \mathrm{ha})$ & 0 & 10 & 50 & 20 & 10 & 10 \\
$4(30 \mathrm{ha})$ & 0 & 10 & 50 & 20 & 10 & 10 \\
\hline
\end{tabular}

Number of offspring per pair varies from 0 to 8 .

Our main purpose is to present this method. We also demonstrate the model by applying it to a hypothetical Ohio landscape containing scattered woodlots of various sizes in which Carolina chickadees (Poecile carolinensis) reside. We chose to model this system because it is currently the focus of a long-term research project (Doherty and Grubb, in prep.). Chickadees must disperse among these woodlots, overwinter, and breed in them. Meanwhile, we assume for the model that the landowner of the woodlots is trying to gain as much income as possible from them without extirpating the birds.

\section{Methods}

\subsection{General model description}

We linked a spatially explicit individual-based simulation model to a dynamic programming model to derive the management choices that will optimize a trade-off between number of birds and economic gain. In general (Fig. 1), a manager undertakes a certain planting or cutting strategy $(j)$ that changes a woodlot distribution from woodlot distribution $(i)$ to woodlot distribution $_{(i j)}$. The spatially explicit individual-based model predicts bird responses to changes in woodlot distribution (the number and sizes of woodlots) caused by these management actions. The outputs from a single time-step of the coupled models are the resulting number of birds and a cost index of revenue lost resulting from the manager's decision to cut or plant woods. Dynamic programming models maximize an objective function, which we have defined as a ratio between ecological gain (in terms of birds) and economic cost (in terms of potential revenue lost by not cutting all the woods).

The dynamic programming model runs by backward iteration and, for any one time step, encompasses all possible combinations of differing landscapes (woodlot distributions) and state variables (variables considered important to the output of the model). The output from the population simulation is used to predict how the bird population will change under the different possible combinations of landscapes and other state variables and incorporates processes such as dispersal among woodlots, woodlot-specific overwinter survival, and woodlotspecific breeding success. The management decision that maximizes the resulting ratio of ecological gain to potential revenue lost is chosen. Because expectations of future gain depend on decisions made in the future, current optimal decisions are based on the assumption that future decisions will also be made under the objectives and constraints of this model, a key feature of these dynamic programming models (Mangel and Clark, 1988). 
Table 5

\begin{tabular}{|c|c|c|c|c|c|c|c|c|}
\hline \multirow[t]{2}{*}{ Woodlot distribution } & \multicolumn{8}{|c|}{ Current number of breeding pairs $\left(x_{t}\right)$} \\
\hline & 30 & 40 & 50 & 60 & 70 & 80 & 90 & 100 \\
\hline a & 60 & 70 & 90 & 100 & 100 & 100 & 100 & 100 \\
\hline b & 50 & 70 & 80 & 90 & 90 & 90 & 100 & 100 \\
\hline$c$ & 60 & 70 & 90 & 100 & 100 & 100 & 100 & 100 \\
\hline $\mathrm{d}$ & 60 & 70 & 90 & 100 & 100 & 100 & 100 & 100 \\
\hline e & 60 & 70 & 90 & 100 & 100 & 100 & 100 & 100 \\
\hline $\mathrm{f}$ & 40 & 40 & 40 & 40 & 40 & 40 & 40 & 40 \\
\hline $\mathrm{g}$ & 50 & 50 & 50 & 50 & 50 & 50 & 50 & 50 \\
\hline $\mathrm{h}$ & 60 & 60 & 60 & 60 & 60 & 60 & 60 & 60 \\
\hline i & 50 & 70 & 80 & 90 & 100 & 90 & 90 & 100 \\
\hline j & 60 & 70 & 90 & 100 & 100 & 100 & 100 & 100 \\
\hline $\mathrm{k}$ & 60 & 70 & 90 & 100 & 100 & 100 & 100 & 100 \\
\hline 1 & 0 & 0 & 0 & 0 & 0 & 0 & 0 & 0 \\
\hline $\mathrm{m}$ & 40 & 40 & 50 & 40 & 40 & 40 & 40 & 40 \\
\hline $\mathrm{n}$ & 50 & 50 & 50 & 50 & 50 & 50 & 50 & 50 \\
\hline 0 & 60 & 60 & 60 & 60 & 60 & 60 & 60 & 60 \\
\hline $\mathrm{p}$ & 0 & 0 & 0 & 0 & 0 & 0 & 0 & 0 \\
\hline
\end{tabular}

Values are means from 10 simulation runs rounded to the nearest 10 pairs. The upper bound on how many bird pairs can be produced is 100 . Production beyond 100 pairs disperses from the area.

We represent this system with four state variables: current woodlot size distribution $(w)$, current number of breeding pairs of chickadees inhabiting these woodlots $(x)$, average number of pairs of birds in the past $(n)$, and average index of revenue foregone from not harvesting timber in the past $(d)$. These last two state variables are important in calculating the true long-term value of different decisions. The single decision variable (i) is the cutting/planting strategy chosen from a discrete set of options. We begin by defining $F(d, n, w, x, t)$ as the maximum expected future reward ratio given that at time $t$ the manager has $d$ average past costs, $n$ average past breeding pairs of chickadees, $w$ current woodlot distribution, and $x$ current number of breeding pairs. The 'maximum expected future reward ratio' is the ratio of average number of birds in the past and average index of revenue foregone in the past measured at some future terminal time $T$ that will result from a course of optimal decisions between times $t$ and $T$, in the future. Thus, $F(d$, $n, w, x, T)$, the terminal reward function, is just $n / d$. We begin at time $T$ and iterate backwards in time, such that at any time $t<T$,

$F(d, n, w, x, t)=\max _{i}\left\{F\left(d^{\prime}, n^{\prime}, w_{i}, x_{i}, t+1\right)\right\}$

where

$$
\begin{aligned}
& d^{\prime}=\left[\frac{t-1}{t} d+\frac{1}{t} d_{i}\right] \\
& n^{\prime}=\left[\frac{t-1}{t} n+\frac{1}{t} x_{i}\right]
\end{aligned}
$$

(these expressions equally weigh economic costs or numbers of birds in each past time step with economic costs or numbers of birds resulting from the current decision $i), w_{i}$ is the woodlot 
distribution resulting from cutting/planting decision $i, x_{i}$ is the number of bird pairs at time $t+1$ resulting from cutting/planting decision $i$ at time $t$, and $d_{i}$ is the index of revenue foregone during time $t$ associated with cutting/planting decision $i$.

\subsection{Example: Carolina chickadees and fragmented forests}

We applied this general framework to the specific problem of how to manage a fragmented forest on an agricultural landscape to minimize economic loss while avoiding extirpating chickadee populations. We chose this hypothetical example because we are familiar with the biology of this animal and are currently working in such a landscape.

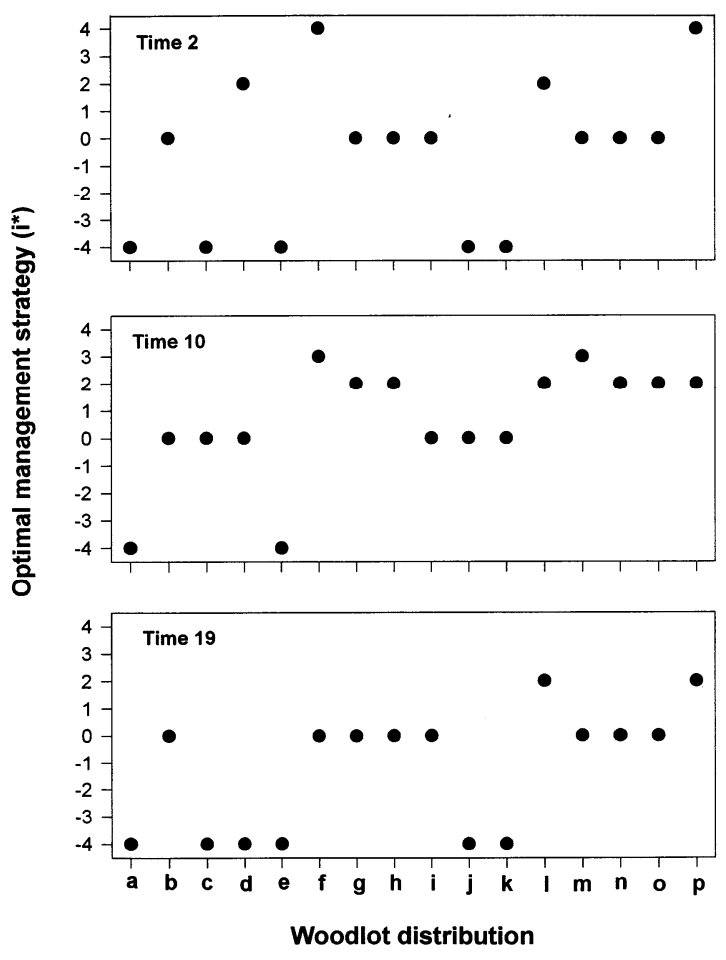

Fig. 3. The optimal management strategy $\left(i^{*}\right)$ for each of the 16 woodlot distributions at times 2,10 , and 19 . At all three times, the index of revenue foregone in the past is 5 , and both the average number of breeding pairs in the past and the current number of breeding pairs are 50 .

Suppose a manager is in charge of a fragmented forest landscape. The manager is mandated to maintain a certain number of breeding pairs of some particular bird species while deriving as much income as possible from harvested timber. It has been estimated that a breeding population lower than 30 pairs is not acceptable because the risk of extinction is too great, but a breeding population of over 100 pairs is more than sufficient to maintain the species in this landscape. Thus, a population between 30 and 100 pairs is acceptable. The landscape of interest is agricultural with many small woodlots and fewer large woodlots isolated by fields. To simplify modeling, the woodlots are assigned to four size classes, 10, 15, 20, and 30 ha. The numbers of woodlots, number of bird territories, and aggregate area of woodland in each size class are given in Table 1. These data are modeled after Carolina chickadee territories in Crawford Co., Ohio. 


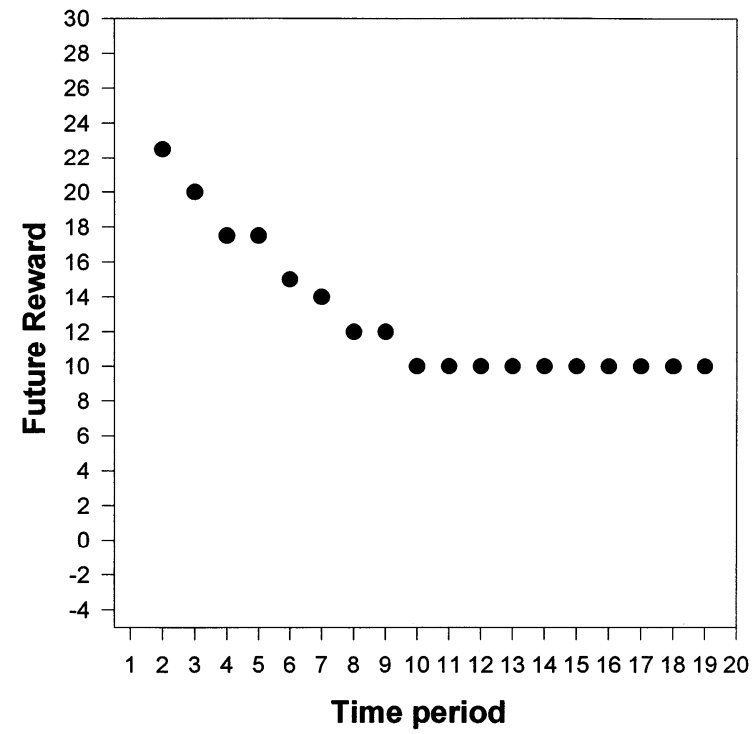

Fig. 4. The terminal reward (at end of period 20) of woodlot distribution $g$ (Fig. 1g) for all time periods. The index of average revenue foregone in the past is 5 , and both the average number of breeding pairs in the past and the current number of breeding pairs are 50 .

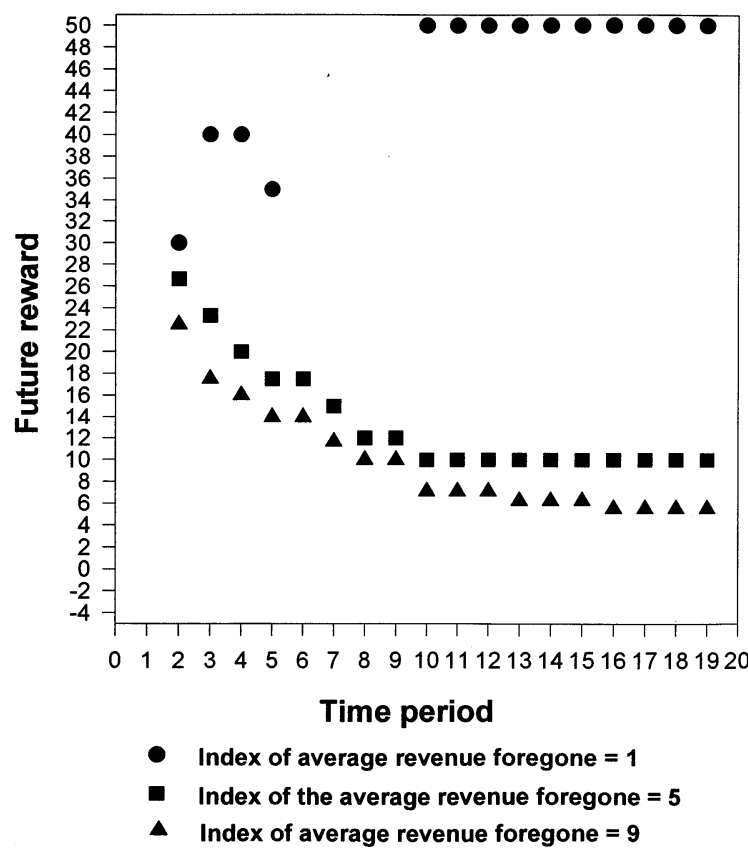

Fig. 5. The future reward for woodlot distribution $a$ (Fig. 2a) for all time periods for three different average values $(1,5,9)$ of the index of past revenue foregone. Both the average number of breeding pairs in the past and the current number of breeding pairs are 50 . 
The manager has nine possible management strategies to choose from ( $i=-4$ to 4 ; Table 2 ) which involve cutting or planting a whole size class, or doing nothing. A cost index (measured in revenue lost, $d_{i}$ ) associated with each action is also given in Table 2. This is an index of the revenue foregone by leaving timber standing. If the manager leaves most of the woodland standing, considerable income is lost because the manager has not harvested it; if the manager leaves little woodland standing, very little revenue is lost. Such an index is narrow and could be more broadly defined as the net change in social welfare including economic benefits associated with habitat protection (Montgomery et al., 1994). The payoff from harvesting small woodlots may not be as great as from harvesting large woodlots due to the cost of moving equipment, and timber on an edge may not be as high in quality as that in the interior. The higher edge/interior ratio in small woodlots would thus make them less valuable. Planting few large woodlots is also assumed to be more expensive than planting many small woodlots due to the costs of acquiring large tracts of land. These assumptions give rise to the relative cost index (Table 2) associated with each management strategy.

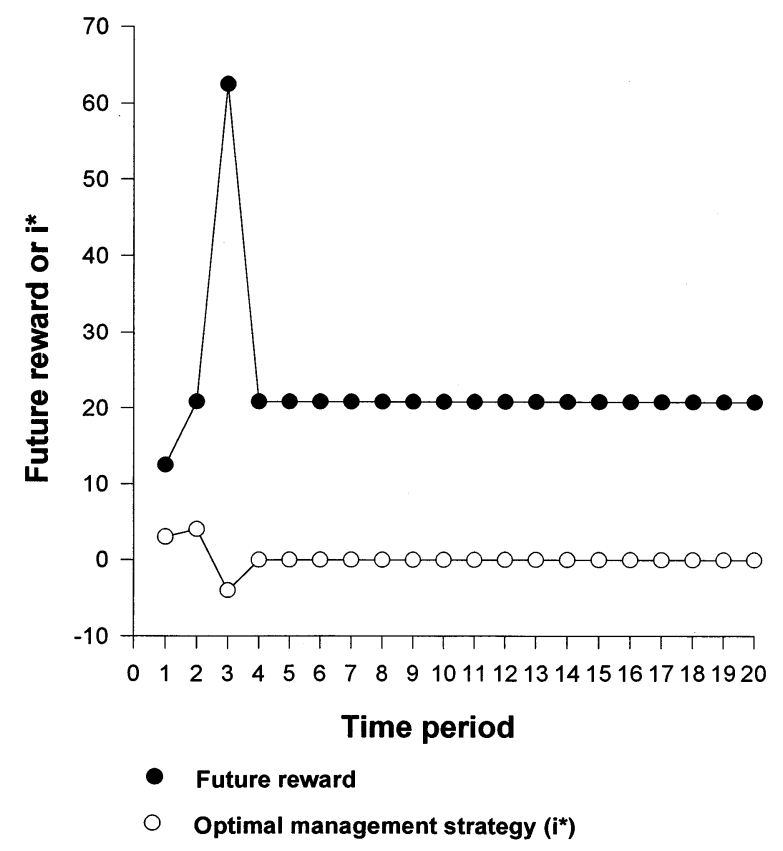

Fig. 6. Woodlot distribution $p$ (initially unwooded landscape, Fig. 1p) followed through time on the optimal path given that at time 1 there were 30 breeding pairs, the lower critical population employed in the model.

The manager is mandated to maintain the $30-100$ breeding pairs of birds at the highest possible net income. Thus, the manager's task is to maximize the birds/revenue-lost ratio. The management horizon is 20 time periods. The length of each time period will depend on the application. For an agricultural field it may be 1 year; for old-growth forest it may be 200 years. In this hypothetical example, it is assumed that after a woodlot is planted, adequate habitat remediation (nest boxes, feeders, some large trees and brush for cover) is in place for the woodlot to be occupied by the bird species within the year. For simplicity we assume that the distribution in Fig. 2a is the maximum aggregate woodland that the agricultural landscape can contain. We also assume that if a size class is absent, it cannot be cut and that if a size class is 
present it cannot be planted. Thus for each time step there are only five alternative strategies. The manager may follow only one single strategy during each time step.

\subsection{The population simulation model}

The objective of this model is to predict how the bird species would fare in landscapes composed of different amounts of woodland distributed among woodlots of various size. The simulation is spatially explicit and based on life history parameters such as woodlot-size-specific reproductive rates, extinction rates, and colonization rates, as well as estimates of dispersal. It is assumed that the manager will cut or plant trees only in late summer and autumn, before dispersal begins.

In Fig. 1, a woodlot distribution $w$ (e.g. Fig. 2a-p) is altered by a management strategy $i$ (Table 2; -4 to 4), which results in a different woodlot distribution $w_{i}$ (Fig. 2a-p). Each of the 16 woodlot distributions (Fig. 2) was modeled over all possible starting bird pairs $(30 \leq x$ pairs $\leq$ 100). At the beginning of a model run, the woodlots were distributed randomly in the landscape. It was assumed that colonization of a territory was a function of both area and isolation of the woodlot. We know that larger and less isolated woodlots are more likely to be colonized than small isolated ones (PFD, pers. obs.) Isolation was defined as the average distance $(\mathrm{m})$ from a territory in a woodlot to the nearest five territories. Territories were ranked by isolation and woodlot area. The highest ranking territories were occupied first.

The probability of surviving the winter was expected to be a function of woodlot area (Table 3). From Bellamy et al. (1996) and our own unpublished data (Doherty and Grubb, in prep.), we have evidence that small birds have a lower probability of survival in small woodlots than in larger woodlots. In the model, survival of a pair was determined by randomly drawing from the associated survival distribution.

Reproductive success was also modeled as a function of woodlot area (Table 4). From other studies (Robinson, 1992) it is known that small woodlots with a high ratio of perimeter to edge are not conducive to reproduction due to edge effects such as predation and brood parasitism. The sum of the reproductive output of all surviving pairs was then calculated, a sum not allowed to exceed 100 pairs, the carrying capacity of the landscape.

Table 5 shows the output from the population simulator model. From 30 to 100 breeding pairs were modeled for all 16 possible woodlot distributions. Each value in the table is a rounded average of 10 runs of the model. Numbers of pairs of birds in Table 5 were used in the dynamic programming model to determine the optimal woodland management strategy.

\section{Results}

Fig. 3 shows the optimal management strategy $\left(i^{*}\right)$ for each woodlot distribution at time steps 2, 10 and 19. As can be seen the optimal choice is not always intuitive. Optimal choices do differ with both different time horizons and different landscapes. For example, no matter when distribution a or e (Fig. 2) occurs, the optimal strategy is to cut the largest woodlot size class. Enough woodlots are left to maintain the birds at $\geq 30$ pairs, and the fewest dollars are lost. In most other distributions, the choice is a function of time, with most planting taking place early.

Fig. 4 shows what the future fitness and optimal choices would be for woodlot distribution $g$ (see Fig. 2) at each time step. As can be seen, if optimal management practices are begun early enough (time 1), then the expected future fitness for management is considerably higher than if the same distribution and state variable values occur at a later starting time (1020). This result suggests that the greater the interval between the time of a manager's decision and the terminal time period the more influence the manager can have on the terminal reward. 
The closer to the terminal time period, the fewer choices the manager will have due to the fewer time steps remaining and because the past practices have more of an influence, resulting in a lower terminal reward. This effect is shown more clearly in Fig. 5 in which woodlot distribution a (Fig. 2) is modeled over all time steps, but with differing amounts of revenue foregone in the past. Further back in time (time 1), all three values for average revenue foregone in the past converge. This suggests that further back in time, the manager has a greater ability to choose optimally and to affect future reward. As the terminal time period approaches, past management practices influence the terminal time more than future practices can, and thus if past revenue lost is high, the future reward will be low as compared to when past revenue lost is low.

Fig. 6 shows what a manager should do when starting out with an unwooded landscape (Fig. 2p). The model suggests that in the first time period, management choice 3 should be followed by planting 15-ha woodlots to allow a breeding population to establish itself. During the next time period, 30-ha woodlots should be planted. Such actions would increase terminal reward by increasing the number of birds. The following time period, the 30 -ha woodlots could be harvested without dropping the bird population below the critical value (30). After the third time period it would not pay to incur the cost of planting more woodland, but to maintain the number of birds, more woods could not be cut.

\section{Discussion}

Linking a dynamic programming model to a population simulator allows a manager to optimize a fitness function at the end of a time period subdivided into a series of time steps. While dynamic programming models have previously been linked to population simulations, this has generally been done in the context of embedding optimal decisions by animals into a population simulation in which all animals are making optimal decisions (Mangel and Clark, 1988). Our approach is quite different. We have embedded a population simulation into an optimal decision model. The population simulation serves to estimate the change in state (in this case, number of breeding pairs) brought about by each potential decision.

For the example given to prove useful in practice, a manager would have to know the average revenue foregone in the past, the average number of breeding pairs in the past, the current number of breeding pairs and the distribution of woodlots, as well as detailed natural history of the organism of interest. With information from the dynamic programming model, a manager could predict the optimal management strategy at different times and different states.

Dynamic programming models would be quite receptive to additional complexity from either the population simulations or added state variables. Also, constraints can be placed on any time step as well as on the terminal reward function if certain values must not go beyond upper or lower limits. In this way protection against variability can be built into the model. The validity of the dynamic model is based on the validity of the parameters and output of the individualbased simulation model.

\section{Conclusions}

With the recent high priority given to threatened and endangered species (Lubchenco et al., 1991), greater pressure is being put on economists and ecologists to work together. Controversies similar to those surrounding the northern spotted owl (Doak, 1989) and Columbia River (Lee, 1993) systems, for which ecologists and economists present very different solutions, are becoming more common (Dixon and Juelson, 1987; Salwasser, 1987; Lee, 1993). In such cases, basic and applied ecologists have warned that continued use of a resource (e.g. cutting oldgrowth forest or damming a river) will threaten species existence (e.g. spotted owls or Pacific 
salmon (Oncorhynchus, spp.)), but some economists and industry analysts have argued that without timber harvests or dams, the negative impacts on job opportunities and regional economic development would be unacceptable (Dixon and Juelson, 1987; Salwasser, 1987; Lee, 1993). There seems little doubt that as human populations continue to expand, managers will require more accurate data on just how much habitat (i.e. how much economic 'loss') is required to maintain viable plant and animal populations. Dynamic programming models can be used to find the optimal balance between conservation and economic concerns. These models can also be adapted to situations in which the life span of the organism of interest is greater than 1 year by increasing both the interval between management decisions and the length over which the simulation is run. Such models could be of great value in protecting the integrity of a species at the lowest economic cost, whether the currency be Dartford warblers (Sylvia undata) per lost Pound Sterling, Japanese cranes (Grus japonensis) per lost Yen, or rhinoceros per lost Krugerand. That is, the general strategy of setting some minimum viable population size and then using models to ask how to maintain such a population size with minimum economic loss should have nearly universal applicability in conservation biology. Using a population simulator linked to a dynamic programming model to accomplish this goal has not been attempted until now, but should prove very useful.

\section{Acknowledgements}

This research was supported by the American Ornithologists' Union, the Maumee Valley Audubon Society, The North American Bluebird Society, The Ohio Chapter of the Nature Conservancy, The Wilson Ornithological Society and NSF grant IBN-9522064 to T.C.G.

\section{References}

Bellman, R., 1957. Dynamic Programming. Princeton University Press, Princeton, 342 pp.

Bellamy, P.E., Hinsley, S.A., Newton, I., 1996. Local extinctions and recolonizations of passerine bird populations in small woods. Oecologia 108, 64-71.

Brawn, J.D., Robinson, S.K., 1996. Source-sink population dynamics may complicate the interpretation of long-term census data. Ecology 77, 3-12.

Costanza, R. (Ed.), 1991. Ecological Economics: The Science and Management of Sustainability. Columbia University Press, New York, 525 pp.

Costanza, R., O’Neil, R.V., 1996. Ecological economics. Ecol. Appl. 6, 975-978.

Dixon, K.R., Juelson, T.C., 1987. The political economy of the spotted owl. Ecology 68, 772-776.

Doak, D., 1989. Spotted owls and old growth logging in the Pacific Northwest. Conserv. Biol. 3, 389-396.

Gillis, D.M., Pikitch, E.K., Peterman, R.M., 1995. Dynamic discarding decisions: foraging theory for high-grading in a trawl fishery. Behav. Ecol. 6, 146-154.

Haight, R.G., 1995. Comparing extinction risk and economic cost in wildlife conservation planning. Ecol. Appl. 5, 767-775.

Jansson, A.M., Hammer, M., Folke, C., Costanza, R. (Eds.), 1994. Investing in Natural Capital: The Ecological Economics Approach to Sustainability. Island Press, Washington, DC, 504 pp.

Kennedy, J.O.S., 1986. Dynamic Programming, Applications to Agriculture and Natural Resources. Elsevier, London, $341 \mathrm{pp}$.

Lee, K., 1993. Compass and Gyroscope, Integrating Science and Politics for the Environment. Island Press, Washington, DC, 243 pp.

Liu, J., 1993. ECOLOCON: an ecological-economic model for species conservation in complex forest landscapes. Ecol. Modelling 70, 63-87.

Liu, J., Dunning, J.B., Pulliam, H.R., 1995. Potential effects of a forest management plan on Bachman's sparrow: linking a spatially explicit model with GIS. Conserv. Biol. 9, 62-75.

Lubchenco, J.A., Olsen, M., Brubaker, L.B., Carpenter, S.R., Holland, M.M., Hubbell, S.P., Levin, S.A., MacMahon, J.A., Matson, P.A., Melillo, J.M., Mooney, H.A., Peterson, C.H., Pulliam, H.R., Real, L.A., Regal, P.J., Risser, P.G., 1991. The sustainable biosphere initiative: an ecological research agenda. Ecology 72, 371-412. 
Mangel, M., Clark, C.W., 1988. Dynamic Modeling in Behavioral Ecology. Princeton University Press, Princeton, $308 \mathrm{pp}$.

McKelvey, K., Noon, B.R., Lamberson, R.H., 1992. Conservation planning for species occupying fragmented landscapes: the case of the northern spotted owl. In: Kareiva, P.M., Kingsolver, J.G., Huey, R.B. (Eds.), Biotic Interactions and Global Change. Sinauer, Boston, MA, pp. 424-450.

Milner-Gulland, E.J., 1997. A stochastic dynamic programming model for the management of the Saiga antelope. Ecol. Appl. 7, 130-142.

Montgomery, C.A., Brown, G.M. Jr., Adams, D.M., 1994. The marginal cost of species preservation: the northern spotted owl. J. Environ. Econ. Manage. 26, 111-128.

Probst, J.R., Weinrich, J., 1993. Relating Kirtland's warbler population to changing landscape composition and structure. Landscape Ecol. 8, 257-271.

Salwasser, H., 1987. Spotted owls: turning a battleground into a blueprint. Ecology 68, 776-779.

Robinson, S.K., 1992. Population dynamics of breeding neotropical migrants in a fragmented Illinois landscape. In: Hagan, J.M., III, Johnson, D.W. (Eds.), Ecology and Conservation of Neotropical Migrant Landbirds. Smithsonian Institution Press, Washington, DC, pp. 408-418.

Whitcomb, R.F., 1977. Island biogeography and 'Habitat islands' of eastern forest. Am. Birds 31, 3-5.

White, B., Wadsworth, R., 1994. A bioeconomic model of heather moorland management and conservation. Ecol. Econ. 9, 167-177. 